\title{
The Impact of Cognitive Tools on the Development of the Inquiry Skills of High School Students in Physics
}

\author{
Mohamed I. Mustafa, \\ Faculty of Education \\ University of Ottawa \\ Ottawa, Canada
}

\author{
Louis Trudel \\ Faculty of Education \\ University of Ottawa \\ Ottawa, Canada
}

\begin{abstract}
-the purpose of the study was to compare the effectiveness of two teaching strategies that utilize two different cognitive tools on the development of students' inquiry skills in mechanics. The strategies were used to help students formulate Newton's $2^{\text {nd }}$ law of motion. Two cognitive tools had been used: a computer simulation and manipulations of concrete objects in physics laboratory. A quasi-experimental method that employed the 2 Cognitive Tools $\times 2$ Time of learning split-plot factorial design was applied in the study. The sample consisted of 54 Grade 11 students from two physics classes of the university preparation section in a high school of the province of Ontario (Canada). One class was assigned to interactive computer simulations (treatment) and the other to concrete objects in physics laboratory (control). Both tools were embedded in the general framework of the guided-inquiry cycle approach. The results showed that the interaction effect of the Cognitive Tools $x$ Time of learning was not statistically significant. However, the results also showed a significant effect on the development of students' inquiry skills regardless of the type of cognitive tool they had used. Although the findings suggested that these two strategies are effective in developing students' inquiry skills in mechanics, students in the computer simulation group had shown larger gain in their inquiry skills test than their counterparts in the laboratory group.
\end{abstract}

Keywords-inquiry skills; teaching strategy; cognitive tools; high school physics; simulation; science laboratory

\section{INTRODUCTION}

A number of difficulties undermines learning science through inquiry, and prevents students from successful engagement in a meaningful investigation. One of the major barriers in inquiry-based learning is the students' lack of adequate level of inquiry skills [1,2,3], such as posing questions and identifying variables, formulating hypothesis, designing and conducting investigations, collecting and analyzing data. Due to an inadequate level of inquiry skills students often learn science through direct observations and problem solving tasks without spending efforts to experience natural phenomena, or construct abilities and knowledge to understand how natural world works [4,5]. Although most relevant research studies provided little guidance about how students acquire and develop these skills over time, some show that factors like students' self-efficacy, effective scaffolding, and collaborative learning environments, and utilization of cognitive tools may have an impact on students' abilities and skills to progress through inquiry tasks [2,5].

Various types of cognitive tools have been identified and explored in terms of their potential usefulness to help students in constructing knowledge, and developing inquiry skills $[1,6,7]$. Great promises have been given to the visualization of natural phenomena via interactive computer simulation [8], and the manipulation of concrete objects in science laboratory [1].

On the one hand, interactive computer simulations provide support for nearly every aspect of scientific inquiry [5]. New computer simulations have evolved now to the point they can contribute to the development of students' learning through inquiry, and allow teachers to meet students' needs more fully [10]. Learners use various types of new simulations to collect, organize and analyze data, transform data into variety of representations, create virtual situations in which they can test hypothesis, and even synthesize and execute their own models $[11,5]$.

On the other hand, a body of research studies has considered inquiry-based laboratory as one of the ways students can understand the natural world of science and develop their inquiry skills $[1,12]$. When a laboratory investigation is constructed in a problem solving context, students will be required to plan a course of action, carry out the activity and collect necessary data, organize and interpret the data, and reach a conclusion. This type of laboratory investigation encompasses both the ways in which understanding is generated within the natural sciences and the approaches to solving problems, as well as attaining inquiry skills and understanding the process of scientific protocols.

Despite the potential advantages of computer simulations and concrete phenomena in enhancing inquiry-based learning, it is important to note that their uses have certain potential drawbacks as well, and therefore, must be taken into consideration. For example, computer-simulated experimentation software dictates the direction of inquiry by predefining variables. Even though simulations can be interactive, students cannot test alternative models or novel variables that are not programmed into the system, so that the opportunity to identify variables on their own is not available $[13,14]$. Also, laboratory work has been criticized and claimed that it is unproductive and confusing. Very often students are 
involved in technical activities (such as assembling the experimental setup) and few opportunities are given to students to present their interpretations and beliefs about natural phenomena [15]. These limitations could prevent students from having an authentic opportunity to develop adequate level of inquiry skills and consequently undermine their efforts to construct new knowledge and engage in inquiry-based learning [9].

Therefore, this study attempts to compare the impacts of two teaching strategies on the development of students' inquiry skills in the domain of physics. One strategy will integrate computer simulation while the other strategy will integrate concrete objects as cognitive tools. In this regard, the main objective is to find out which learning tool is more suitable to help students develop their inquiry skills and in which learning circumstances. Accordingly, the following research questions are designed to guide the study:

1) What are the possible impacts of the visualization of Newton's second law of motion via interactive computer simulation on the development of students' inquiry skills?

2) What are the possible impacts of the manipulation of concrete objects to perform Newton's second law experiment on the development of students' inquiry skills?

3) How are the effects of the utilization of computer simulation and the manipulation of concrete objects compared?

\section{THOERETICAL FRAMWORK}

The theoretical framework of this study is based on the social constructivist approach of learning. Piaget [16] argued that learners are constantly constructing and reconstructing knowledge in their efforts to maintain a coherent system of interpretation [17]. Also, they are capable of performing at higher intellectual levels when they are guided by an experienced person and asked to work in collaborative situations [18]. We argue that learners, in a guided-inquiry environment, need to acquire an appropriate level of inquiry skills in order to accomplish inquiry tasks and phases successfully. One of the ways to achieve that relies on the opportunities given to students to learn with cognitive tools such as computer simulation or concrete objects in science laboratory.

When cognitive tools present natural phenomena as real-life problems, they provide feedback to students on their attempts to solve these problems. In the context of learning, feedback and reflection weigh students' performances while obtaining data, as well as their predictions about the outcomes of the investigation $[19,6]$. The argument is that, while students are investigating natural phenomena, they receive feedback not only from an experienced person (like teacher, or a capable peer), but also from their performances associated with cognitive tools. Accordingly, they may feel a need to adjust their performance in response to it. This is expected to raise students' awareness of their inquiry skills deficiencies and encourage them to think how to correct them.
Therefore, students tend to engage in inquiry investigations repeatedly to practice their inquiry skills and consolidate them in each engagement [7].

Furthermore, teacher guidance and peer interaction will present additional experiences that would lead students to complete their inquiry tasks and phases more efficiently.

Consequently, the integration of cognitive tools in guidedinquiry approach is expected to develop students' inquiry skills. Therefore, the main purpose of the study is to compare the effectiveness of two teaching strategies embedding two cognitive tools: visualization of natural phenomena via interactive computer simulation and manipulation of concrete objects in a physics laboratory on the development of students' inquiry skills in the context of Newton's $2^{\text {nd }}$ law of motion.

\section{TEACHING STRATEGIES}

\section{A. Teaching and Learning Objectives}

The overall learning objectives are set for students to "demonstrate scientific investigation skills (related to both inquiry and research) in the four areas of skills: initiating and planning, performing and recording, analyzing and interpreting" [20, p.182]. Throughout the learning activities, students are expected to develop inquiry skills to be able to [20]:

1) Identify variables such as forces, mass, time, etc.; and

2) Design and conduct an inquiry to analyze the effect of forces acting on objects in one dimension, using vector diagrams, free-body diagrams, and Newton's laws. During the inquiry investigation, students are expected to use their assigned cognitive tool (concrete objects or computer simulation) to analyze, in quantitative terms, the relationships between two variables when a third is kept constant (e.g., relationships between acceleration and applied force when the mass is kept constant). So in the end, students are expected to formulate Newton's Second Law in their own.

The teaching objectives, therefore, will primarily be looking at ways to foster the development of students' inquiry skills and guide them to accomplish their inquiry tasks successfully.

\section{B. The Cognitive Tools}

The cognitive tools and materials are basically selected to support the development of students' inquiry skills.

- Computer simulation: The computer simulations are selected from the ones available on the Physics Education Technology (PhET) website (http://phet.colorado.edu/index.php). They are developed and tested by Physics Education Technology (PhET) project. Three interactive simulations have been selected from PhET website: Force in One Dimension [21], The Ramp [22], and Moving Man simulations [23]. As an example, the window of the first simulation is shown in figure 1. 


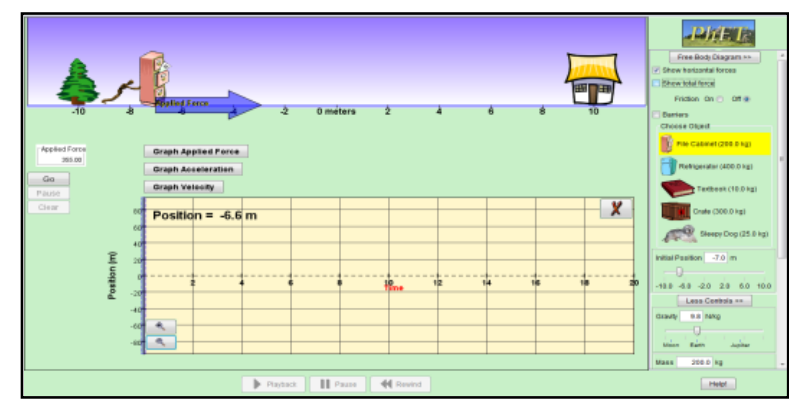

Fig. 1. Main window of Force in one dimension

- Concrete objects: The concrete objects are laboratory apparatus that are selected from the many physics activities available in grade 11 textbooks [24]. The concrete objects include dynamic cart, set of known masses, ticker-tape timer, banked ramp, and spring balance (fig. 2).

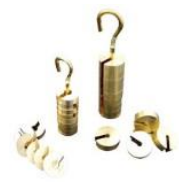

Known masses

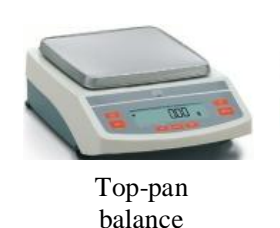

balance

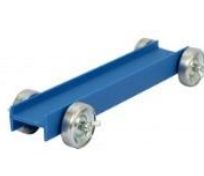

Dynamic cart

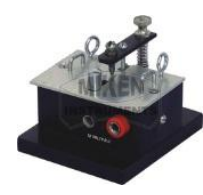

Ticker tape timer
Fig. 2. A set of concrete objects used for Newton's second law activities

\section{The Implementation of teaching strategies}

Both strategies used the 5Es learning cycle- engage, explore, explain, elaborate, and evaluate- [25] in a similar way except in the implementation of the assigned cognitive tool. Before engaging students in the 5Es cycle, the teacher took the first day to organize students in small groups and train them with their assigned cognitive tool. The training session is designed as a learning activity, so students can monitor their progression and practice their abilities within a learning context. During the phases of 5Es cycle, both classes used identical instructional materials and inquiry tasks. Those tasks consist for each phase of the 5Es cycle:

- Engage: Reading a story-telling and respond to the associated questions. Posing questions to be investigated in the next phase.

- Explore: Designing and conducting an inquiry into the relationship between the acceleration of an object and its net force and mass.

- Explain: Analyzing the relationships between acceleration and applied forces.

- Elaborate: Conduct an inquiry that applies Newton's laws to analyze, in qualitative terms, the forces acting on an object, and use free-body diagrams to determine the net force and the acceleration of the object.
- Evaluate: The questions presented at the end of phase of the 5Es cycle are designed to evaluate students' progress.

The main difference between the simulation and the physics laboratory were mostly to be found firstly in the exploration phase of the 5Es cycle and secondly in the elaboration phase.

Firstly, in the exploration phase, the simulation provides controls that allow students to create virtual objects, change variables and control others and study the trend of the resulting type of motion in forms of graphical representations (fig. 3). In the other hand, in the physics laboratory, students were given concrete objects to manipulate and it allows students to observe the motion of real objects (Fig. 4).

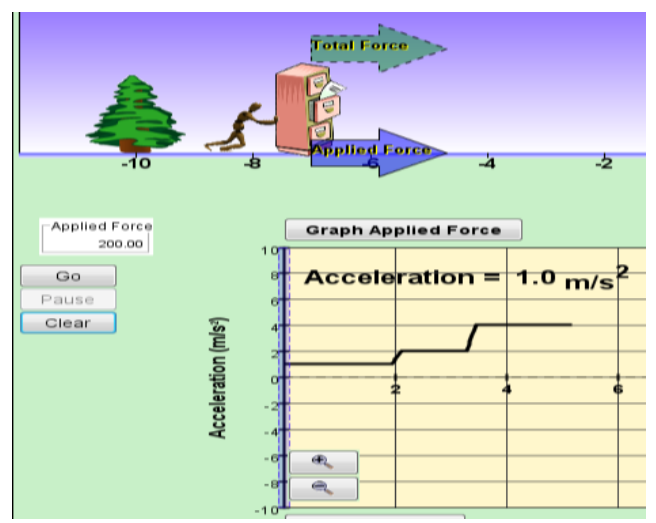

Fig. 3. Force in 1D simulation

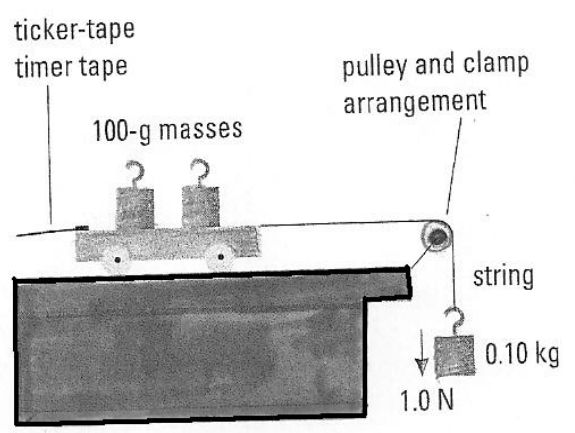

Fig. 4. An experimental setup used to simulate the motion of a cart in a horizontal plane

Secondly, in the elaboration phase, the simulation allows students to test the motion of an object in a frictionless inclined plane and provide them with free body diagrams to study various aspects of motion. In the other hand, the physics laboratory allows students to create different setups to test the motion of an object in a rough inclined plane, and as a consequence, they could observe directly the motion of real objects in an inclined plane.

With respect to the organisation and unfolding of the activities, the two teaching strategies differed notably. In the simulation strategy, students worked in small groups. They used Force in one dimension simulation to test their predictions by making cause and effect relations between force, mass, and acceleration. The simulation contains controls that allow 
students to create objects with which they can associate net force, mass, and acceleration as variables. Next, students presented their own explanations that made sense of their observational data, and establish relationships between net force, mass, and acceleration to state Newton's 2nd law of motion in words and symbols. The teacher had guided the students through their data collection part and provided hints to keep them focused and on task. Small-group and whole-class discussions followed that have focused students on the conclusions they made to reach a consensus about the relationships between net force, acceleration, and mass.

In the laboratory strategy, students worked in 4-member groups. They designed an experimental setup (fig. 4) to analyze the motion of a cart and establish the relationship between the net force acted on the cart, its acceleration, and mass. The teacher guided students through the same scaffolded learning events that the teacher would have used with students in the simulation group.

\section{Methodology}

The ideal method would be to compare, in a quasiexperimental design, the development of students' inquiry skills in two learning environments: one with an interactive computer-based simulation, and the other with concrete objects and materials in a physics laboratory. Accordingly, the following hypotheses were postulated and computed at the 0.05 level of significance:

Hypothesis 1: students taught via inquiry-based computer simulation will significantly develop their inquiry skills better than students taught via inquiry-based laboratory.

Hypothesis 2: students taught via inquiry-based laboratory will significantly develop their inquiry skills better than students taught via inquiry-based computer simulation.

Hypothesis 3: students taught via inquiry-based laboratory and inquiry-based computer simulation will significantly develop their inquiry skills.

With respect to the sample, 54 students have been conveniently selected from grade 11 - university preparation section from a high school in Ottawa. Without disturbing the school academic plan, this study was conducted during the first semester of school academic year $2010-2011$. The content of the study was the regular physics course for grade 11 university preparation section, developed by Ontario Ministry of Education, and facilitated by a high school physics teacher. The participating students came from two naturally formed classrooms (each of approximately 27 students). Both groups conducted "Force in one dimension", one of the experiments in Ontario Curriculum - Physics [20]. One group was randomly assigned to a computer-based environment, and the other one to a physics laboratory environment.

With respect to the research design, the independent variable was the learning tool factor with two levels: the simulation and the laboratory. The dependent variable consists of a test of integrated process skills (TIPS II). According to their authors, the test exhibits a total test reliability of 0.86 [26]. A two-way split-plot design was performed to examine if there was a significant statistical difference between the means of students' scores in the pre- and post-TIPS (II) [26]. The number of questions answered correctly in the TIPS (II) served as the dependent variable in a 2 Learning Tool $\times 2$ Time splitplot Analysis of Variance (ANOVA).

The 2 levels of the learning Tool factor (between-subjects) consist of, as explained before, the interactive computer simulation and the physics laboratory; and the Time of test factor (within-subjects) will have two levels: pre- and postNewton's second law activities. Additionally, another variable has been added to perform a one-way ANOVA comparing MDT scores, Mechanics Diagnostic Test [27], of participants in the two Learning Tools conditions to ensure no pre-existing differences in conceptual understanding, and therefore, was considered as a covariate factor.

\section{RESUlTS}

\section{A. Descriptive}

The descriptive results of the MDT showed that students from both groups, in average, have similar levels of conceptual understanding in mechanics (Table 1).

TABLE I. Mechanics Diagnostic Test Results By Groups

\begin{tabular}{|l|l|l|l|}
\hline Group & $\mathrm{N}$ & Mean & Std. Deviation \\
\hline Laboratory & 24 & 11.50 & 2.844 \\
Interactive simulation & 25 & 11.12 & 2.166 \\
Total & 49 & 11.31 & 2.502 \\
\hline
\end{tabular}

The figure 5 describes two plots representing the means of students' scores in the pre- and post-skills test in laboratory group and simulation group. The graph shows an increase in the means in both groups. However, it appears that the line graph of the simulation group is steeper than that of the laboratory group. It seems that students in the simulation group obtained a slightly higher gain in TIPS scores than students in the laboratory group, despite the fact that the graph of the simulation group was lower than that of the laboratory group.

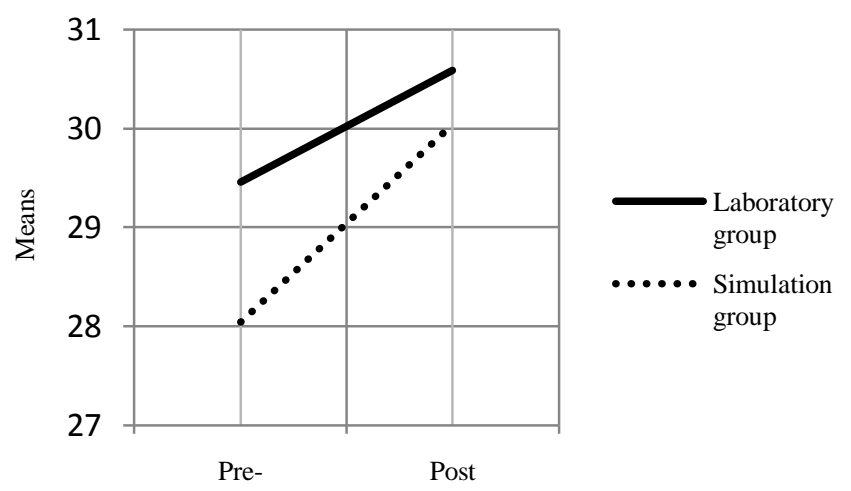

Fig. 5. Inquiry Skills Test (TIPS II)

\section{B. Inferential statistics}

The results of one-way ANOVA (Table. 2) supported the initial screening with the physics teacher and showed that students across the two groups were not significantly different 
in their level of conceptual understanding $(\mathrm{F}(1,47)=0.278)$. Therefore, the students' MDT scores did not threaten the relationship between learning tool (independent factor) and students' scores of TIPS (II) (dependent factor).

TABLE II. TABLE 2 ONE-WAY ANOVA TEST

\begin{tabular}{|l|l|l|l|l|l|}
\hline & $\begin{array}{l}\text { Sum of } \\
\text { Squares }\end{array}$ & Df & $\begin{array}{l}\text { Mean } \\
\text { Square }\end{array}$ & F & Sig. \\
\hline $\begin{array}{l}\text { Between } \\
\text { Groups }\end{array}$ & 1.768 & 1 & 1.768 & $0.278^{*}$ & 0.600 \\
\hline $\begin{array}{l}\text { Within } \\
\text { Groups }\end{array}$ & 298.640 & 47 & 6.354 & & \\
\hline Total & 300.408 & 48 & & & \\
\hline p $<.05$ & \multicolumn{5}{|l}{} \\
\hline
\end{tabular}

A 2 Learning Tool $\times 2$ Time split-plot repeated measures ANOVA analysis (Table 3) showed that the interaction effect was not significant $(\mathrm{F}(1,47)=1.349)$. This suggested that the effect of learning activities over time on the development of student inquiry skills did not depend on the type of learning tools used during the activities. Hence, hypotheses 1 and 2 were rejected.

TABLE III. SPLIT-PlOT LEARNING TOOL $\times$ TIME ANALYSIS OF VARIANCES

\begin{tabular}{|c|c|c|c|c|c|}
\hline Source & $\begin{array}{l}\text { Type III Sum } \\
\text { of Squares }\end{array}$ & df & $\begin{array}{l}\text { Mean } \\
\text { Square }\end{array}$ & $\mathrm{F}$ & Sig. \\
\hline & \multicolumn{5}{|c|}{ Between subjects } \\
\hline Intercept & 85424.86 & 1 & 85424.86 & 3300.7 & 0.000 \\
\hline $\begin{array}{l}\text { Learning } \\
\text { Tool }\end{array}$ & 23.56 & 1 & 23.56 & $0.910^{*}$ & 0.345 \\
\hline \multirow[t]{2}{*}{ Error } & 1216.40 & 47 & 25.88 & & \\
\hline & \multicolumn{5}{|l|}{ Within subjects } \\
\hline $\begin{array}{l}\text { Time (pre- } \\
\text { and post) }\end{array}$ & 59.79 & 1 & 59.79 & $17.207^{* *}$ & 0.000 \\
\hline $\begin{array}{l}\text { Learning } \\
\text { Tool } \times \text { Time }\end{array}$ & 4.69 & 1 & 4.69 & $1.349^{\text {*** }}$ & 0.251 \\
\hline Error (time) & 163.31 & 47 & 3.48 & & \\
\hline
\end{tabular}

The repeated measures test (Table 3 ) also showed that there was no significant main effect for the Learning Tool $(\mathrm{F}(1,47)=$ 0.910). This suggests that the type of learning tool did not significantly influence the development of student's inquiry skills. However, the repeated measures test revealed a significant main effect for the within-subjects factor $(\mathrm{F}(1,47)=$ 17.207). This suggested that there was statistically significant difference between students' scores in the pre-TIPS (II) and the post TIPS (II), regardless of what type of learning tool they had used in Newton's second law activities. Therefore, hypothesis 3 was supported.

\section{DISCUSSION}

The results of this research showed that in a guided inquirybased learning environment, visualization via interactive computer simulations or manipulation of concrete objects in a physics lab can both be used as a learning tool to develop students' inquiry skills in mechanics. The positive effects of these intellectual learning tools (mind-tools) in supporting the development of students' inquiry skills are consistent with the cognitive tools that support structures that aim to compensate for students' knowledge or inquiry skills deficiencies $[6,4]$.
Despite the fact that the two learning tools did not show a statistically significant difference, subjective observations of the classroom environment made by the researcher may give some insights on the effectiveness of the computer simulation and the manipulation of concrete objects. For example in their attempts to establish relationships between net force, mass, and acceleration, the students in computer simulation group not only had the chance to manipulate the values of net force and observe the resulting type of motion several times, but they also visualized the effect of specific components of the net force on the acceleration of an object, which they would not have identified if they were to manipulate concrete objects. In contrast, students in the physics laboratory were given opportunities to manipulate concrete objects, which provided real experiences with natural phenomena (motion of a dynamic cart) that allowed students to study what influenced the motion (acceleration) of a dynamic cart.

However, prior research has shown that the development of inquiry skills is typically difficult to achieve in a short timeeffect of inquiry instruction, and it is always challenged by the abilities of students to self-direct (self-regulate) their inquiry investigation [28]. This view was noticed during this study as well. In this regard, different challenges have been recorded from the researcher's diary, and from students' booklets including observational errors, instrumental errors, long time on task, and lack of operational skills.

The major part of the above stated challenges, however, was compensated by a successful implementation of other components of the teaching strategy such as quality of Students' booklets, collaboration setting, and the physics teacher scaffolding.

\section{CONCLUSION}

The results of the study showed that there were no significant interaction effects between the types of learning tool used during the activities and the development of the students' inquiry skills measured by the pre-TIPS (II) and the post TIPS (II). Students from both conditions significantly developed their inquiry skills over the time provided for the learning activities. From this, the students' level of conceptual understanding in mechanics did not influence their efforts to develop their inquiry skills.

The answer to the first research question concluded that computer simulations hold promises to assist students in identifying and establishing relationships between variables. Working with computer simulations allows students to work independently and save valuable class time for other learning activities. It should be noted, however, that the current simulations may not promote real experiences with natural phenomena.

The second research question concluded that, with careful guidance students can benefit from manipulation of concrete objects in a science laboratory. Students can challenge their ideas against natural phenomena and observe how it actually works, practice different components of inquiry skills, and realize how scientists work in real life. A successful laboratory experiment however, requires good preparation and longer time to perform, which may not be possible at all times. 
All in all, if technology is used in balance with real experiences and is placed in its proper context, it can enrich the classroom by providing new and contrasting contexts in which to understand experiences [13].

Despite that, the study has certain limitations that should be taken into consideration when interpreting the results. The limitations pertain to the following:

- The study did not take students' diversity into account, which made the results less conclusive from the point of view of gender, physical abilities, and cultural background.

- The small sample size limits the study's generalizability therefore, the results are subjected to the conditions and learning circumstances that occurred during this study.

- The teaching strategy embedded two learning tools to tackle the five inquiry skills. The results were not specific enough to identify which particular inquiry skill has led the overall improvement.

\section{FUTURE WORK}

The results from this study present further research opportunities including how the development of inquiry skills might support students' efforts to understand physics concepts and principles; what aspects of teaching strategies afford opportunities for the development of inquiry skills; what kind assessment tools are required on inquiry investigation; and how new teaching strategies imparting learning science as inquiry. Furthermore, the study present research opportunities regarding the methods that should be used to prepare teachers to teach science as inquiry, and what skills teachers should acquire to be able to guide students through inquiry learning.

\section{REFERENCES}

[1] A. Hofstein, "Providing high school chemistry students with opportunities to develop learning skills in an inquiry type laboratory: a case study", International Journal of Science Education, vol. 26, no 1, pp. 47-62, 2004

[2] D. Ketelhut, "The impact of student self-efficacy on scientific inquiry skills: An exploratory investigation in River City, a multi-user virtual environment", Journal of Science Education and Technology, vol. 16, no 1, pp. 99-111, 2007

[3] D. Kuhn, and M. Pease, "What needs to develop in the development of inquiry skills?", Cognition and Instruction, vol. 26, pp. 512-559, 2008.

[4] S. Manlove, A. Lazonder and T. de Jong, "Regulative support for collaborative scientific inquiry learning", Journal of Computer Assisted Learning, vol. 22, pp. 87-98, 2006.

[5] S. Khan, "New Pedagogies on Teaching Science with Computer Simulation", Journal of Science Education and Technology, vol. 20, no 3, pp.215-232, 2011.

[6] D. Jonassen, Computer in the Classroom: Mindtools for Critical Thinking. Englewood Cliffs, NJ: Merrill, 1996

[7] D. Kuhn, and D. Dean, "Is developing scientific thinking all about learning to control variables?", Psychological Science, vol. 16, no 11, pp. $866-870,2005$.
[8] S. Abdullah, and M. Abbas, "The effects of inquiry-based computer simulation with cooperative learning on scientific thinking and conceptual understanding", Malaysian Online Journal of Instructional Technology (MOJIT), vol. 3, no 2, pp. 1-16, 2006.

[9] P. Brown, S. Abell, A. Demir, and F. Schmidt, "College Science Teachers' Views of Classroom Inquiry”, Science Education, vol. 90, no 5, pp. 784-802, September (2006).

[10] S. Foti, and G. Ring, G. (2008). "Using a simulation-based learning environment to enhance learning and instruction in a middle school science classroom", Journal of Computers in Mathematics and Science Teaching, vol. 27, no 1, pp. 103-120, 2008.

[11] P. Kubicek, "Inquiry-based learning, the natural of science, and computer technology: New possibilities in science education", Canadian Journal of Learning and Technology, vol. 31, no 1, Winter (2005).

[12] M. Kipnis, and A. Hofstein, "The inquiry laboratory as a source for development of metacognitive skills", International Journal of Science and Mathematics Education, vol. 6, pp. 601-627, 2007.

[13] T. Machet, D. Lowe, and C. Gütl, "On the potential for using immersive virtual environments to support laboratory experiment contextualisation", European Journal of Engineering Education, vol. 37, no 6, pp.527-540, December (2012).

[14] B. Dalgarno, and M. Lee, "What are the learning affordances of 3-D virtual environments?", British Journal of Educational technology, vol. 41, no 1, pp. 10-32, January (2010).

[15] P. Knipp, "Broadcasting a lab measurement over existing conductor networks", The Physics Teacher, vol. 47, no 7, pp.471-473, 2009.

[16] J. Piaget, "Cognitive development in children: Development and learning", Journal of Research in Science Teaching, vol. 2, pp. 176-186, 1964.

[17] B. Davis, D. Sumara, and R. Luce-Kapler, Engaging minds: Changing teaching in complex times, 2nd Edition, NY: Routledge, 2008.

[18] L. Vygotsky, Mind in society: The development of higher psychological processes. Cambridge, MA: Harvard University Press, Wadsworth Publication Company, 1978.

[19] J. Dewey, Experience and Education. Kappa, Indiana: Delta Pi, 1938.

[20] Ministry of Education, The Ontario Curriculum Grades 11 and 12 (Revised). Retrieved from Ontario Ministry of Education's website at www.edu.gov.on.ca, 2009

[21] PhET University of Colorado (2009). Forces in 1 Dimension. Interactive Simulations. Retrieved August 15, 2010, from http://phet.colorado.edu.

[22] PhET University of Colorado (2009). The Ramp. Interactive Simulations. Retrieved August 15, 2010, from http://phet.colorado.edu.

[23] PhET University of Colorado (2010). The Moving Man. Interactive Simulations. Retrieved August 15, 2010, from http://phet.colorado.edu.

[24] M. DiGiuseppe, "Nelson Physics 11: University Preparation". Scarborough, ON: Nelson Education, 2012.

[25] J. Renner, 'Investigation in natural science: Biology teachers' guide". Report: ED260927, 177 pp., 1985

[26] J.C. Burns, J. R. Okey, and K.C. Wise, K. C., "Development of an integrated process skills test: TIPS (II)", Journal of Research in Science Teaching, vol. 22, no 2, pp.169-177, 1985.

[27] I. Halloun, "Common sense concepts about motion", American Journal of Physics, vol. 53, no 11, pp. 1056-1065, 1985.

[28] E. Scanlon, S. Anastopoulou, L. Kerawalla, and P. Mulhalland, "How technology resources can be used to represent personal inquiry and support students' understanding of it across contexts", vol. 27, no 6, pp.516-529, 2011. 